\title{
ESTRATÉGIAS E INDUTORES DA \\ INTERNACIONALIZAÇÃO DAS COOPERATIVAS AGROPECUÁRIAS: \\ o caso paranaense
}

1- Claudia Monica Ritossa*

Doutoranda em Administração pela Universidade Federal do Paraná - UFPR, Curitiba/PR, Brasil.

Professora da Universidade Positivo - UP, Curitiba/PR, Brasil.

ritossa@gmail.com

http://lattes.cnpq.br/7840724464472072

\section{2- Jane Mendes Ferreira}

Doutoranda em Administração pela Universidade Positivo - UP, Curitiba/PR, Brasil.

Professora da Universidade Estadual de Ponta Grossa - UEPG, Ponta Grossa/PR, Brasil.

janemff@yahoo.com.br

http://lattes.cnpq.br/4240421546504397

\section{3- Eduardo Angonesi Predebon}

Douturando em Administração pela Universidade Federal do Paraná - UFPR, Curitiba/PR, Brasil.

Professor do Instituto Federal de Educação, Ciência e Tecnologia do Rio Grande do Sul - IFRS, Bento Gonçalves/RS, Brasil.

epredebon@ufpr.br

http://lattes.cnpq.br/5006360427924464 


\section{ESTRATÉGIAS E INDUTORES DA INTERNACIONALIZAÇÃO DAS COOPERATIVAS AGROPECUÁRIAS: O CASO PARANAENSE}

\section{RESUMO}

Este artigo contribui com a teoria e prática das cooperativas agropecuárias ao apresentar um modelo voltado à análise de estratégias de internacionalização, dando suporte à formulação e avaliação destas estratégias. Para tanto, este artigo pretende impulsionar a ampliação e a diversificação das cooperativas agropecuárias e do agronegócio, agregando maior valor à produção local, além de expandir o comércio exterior brasileiro. Nesse sentido, foi realizado um levantamento de campo, exploratório e descritivo, ex post facto, com corte transversal e método de interrogação/comunicação para a coleta de dados. $\mathrm{O}$ artigo demonstra que o processo de internacionalização das cooperativas agropecuárias está aprimorando a qualidade da produção agropecuária, modernizando seus sistemas e tecnologias, e certificando seus produtos. Encerra-se o artigo com conclusões práticas e recomendações para aplicações futuras similares.

\section{Palavras-Chave}

Estratégias de internacionalização; estratégias de diversificação; cooperativas agropecuárias.

\section{STRATEGIES AND INDUCTORS OF INTERNATIONALIZATION OF AGRICULTURAL COOPERATIVES: THE CASE OF PARANA}

\section{ABSTRACT}

This article contributes to theory and praxis of agricultural cooperatives presenting a model for the analysis of internationalization strategies, evaluating the feasibility of these strategies. To this end, the article intends to provide an impulse to the diversification of agricultural cooperatives and agribusiness so as to add more value to local production and expand Brazil's foreign trade. Therefore, it was performed a crosssectional, exploratory and descriptive, ex post facto field survey, with a questioning/communication method for data collection. The article demonstrates that the internationalization process of the agricultural cooperatives is improving its agricultural and livestock produce, modernizing its systems and technology, and certifying its products. The article closes with practical conclusions and recommendations for similar, future applications.

\section{Keywords}

Internationalization strategies; diversification strategies; agricultural cooperatives. 


\section{Introdução}

Nas últimas duas décadas, mudanças estruturais profundas marcaram o desenvolvimento do agronegócio brasileiro e, conseqüentemente, das cooperativas agropecuárias nacionais. Uma nova realidade competitiva decorrente da abertura comercial, da desregulamentação dos mercados, dos processos de integração econômica regional e das crises econômicas internacionais redesenhou a arquitetura do comércio exterior mundial.

Nesse contexto, despontam alguns fatores que impulsionam quaisquer organizações a ingressarem em um processo de internacionalização, como: desejo de expansão de mercados, acesso a recursos naturais, busca da eficiência das operações atingindo escala mundial, entre outras. Independentemente da motivação, no entanto, a organização ao optar pela internacionalização se vê diante de diversos desafios, entre os quais a busca por informações sobre o processo de internacionalização. Mercados globalizados e, por consequência, concorrência intensificada, colocam a estratégia de internacionalizar os negócios na agenda de opções estratégicas das organizações, quaisquer que sejam o seu tamanho, atividade ou forma organizacional. Nesse cenário, as pesquisas sobre tal processo apresentam-se como fator relevante.

Entretanto, tradicionalmente, as investigações sobre os fatores e modelos utilizados nos processos de internacionalização das organizações têm utilizado as grandes corporações como objeto prioritário de estudo. Tal realidade tem limitado as possibilidades de avanço nas pesquisas sobre as peculiaridades inerentes aos fatores que estão envolvidos na internacionalização de outros tipos de organização, tais como as cooperativas agropecuárias.

A implicação da escassa disponibilidade de pesquisa sobre o processo de internacionalização de outros tipos de organização é prática para os estrategistas porque os subsídios para a tomada de decisão são limitados o que pode tornar ainda mais, difícil e complexo a decisão estratégica de atuar fora das fronteiras nacionais. Além de estratégica para as organizações, a decisão de internacionalizar também tem implicações para o Brasil porque pode auxiliar no desenvolvimento econômico da nação. Para Rocha e Freitas (2004), os países se beneficiam da atuação internacional de suas empresas, uma vez que, ao menos nas economias capitalistas, países não negociam com países, mas empresas de um país negociam com empresas de outros países.

Nesse cenário, as cooperativas agropecuárias aparecem como organizações que podem auxiliar no desenvolvimento econômico da nação e, por outro lado, como aquelas que também necessitam de modelos, estudos e apoio que facilitem o seu processo de internacionalização.

As cooperativas agropecuárias são responsáveis por cerca de $40 \%$ do Produto Interno Bruto (PIB) agrícola nacional e $6 \%$ das exportações do setor (ORTIZ, 2007). No Paraná, estado com tradição e vocação para a atividade rural, $53 \%$ da economia agrícola advém do cooperativismo agropecuário que responde por, aproximadamente, 18\% do Produto Interno Bruto (PIB) (OCEPAR, 2006). Esse segmento, de acordo com dados da Organização das Cooperativas do Estado do Paraná (OCEPAR, 2007), exportou em 2006 o equivalente a US\$ 852,9 milhões, representando 30,1\% do total das exportações das cooperativas brasileiras e $8,5 \%$ do total de exportações do Estado.

Ao mesmo tempo em que se verifica a internacionalização de cooperativas agropecuárias como uma tendência mundial, ela também se apresenta como um dos seus principais desafios (DONOSO et al, 2003). Ao privilegiar indivíduos ao invés do capital, as cooperativas, geralmente, não se expandem para além das fronteiras nacionais. Contudo, a intensificação da concorrência nos mercados local e internacional e a oferta de novas oportunidades nas economias dos países em desenvolvimento, impõem às cooperativas a necessidade de formular novas estratégias que, igualmente, protejam mercados tradicionais e permitam a conquista de novos negócios. Algumas questões particulares trazem implicações, positivas e negativas, para as atividades internacionais da cooperativa. Vender lá fora, apesar da concorrência, pode oferecer novas alternativas de comercialização. O exemplo mais recente é a questão energética mundial que vem remodelando o fluxo de comercialização do milho, abrindo espaço para o crescimento da produção e das exportações da cooperativa.

Assim, diante da complexidade e implicações inerentes à decisão estratégica de internacionalizar as atividades das organizações, além da escassez de investigações sobre o tema (DONOSO et al, 2003) e da crescente relevância do cooperativismo no saldo da balança comercial brasileira, a presente investigação tem por objetivo verificar quais as estratégias de internacionalização das cooperativas agropecuárias sob análise e identificar os fatores que motivam e facilitam essa atividade para esse segmento. 
Mais especificamente, este estudo volta-se para os aspectos favoráveis à adoção de estratégias de internacionalização por parte das cooperativas do Estado do Paraná, um dos maiores exportadores do agronegócio nacional. Fatores como a globalização e a liberação do comércio, desencadearam mudanças no ambiente político, social e econômico no qual as cooperativas agropecuárias estão inseridas; a decisão estratégica de internacionalizar tornou-se de fundamental relevância na busca de alternativas que incrementem a eficiência empresarial da cooperativa e possibilitem a oferta de melhores serviços aos seus associados (FAO, 2001)

Este artigo está divido em cinco seções. A próxima seção apresenta os fundamentos conceituais que amparam este estudo. A segunda seção detalha as considerações metodológicas. Na terceira seção, discutem-se os resultados. Na quarta seção, são apresentadas algumas conclusões e considerações. Finalmente, apresentam-se sugestões para pesquisas futuras.

\section{Fundamentos Conceituais}

O arcabouço teórico que fundamenta este estudo segue disposto em três subitens: cooperativas, estratégias de internacionalização e fatores motivadores e facilitadores das atividades internacionais.

\subsection{Cooperativas}

O movimento cooperativo tem suas raízes tradicionalmente ligadas à Inglaterra, mais especificamente a Rochdale, uma cidade de trabalhadores de tecelagem, em 1844. Passados mais de 160 anos, o conjunto de princípios que norteou os fundadores, continua sendo a diretriz do cooperativismo praticado em todos os países. Por seu intermédio, os valores de ajuda mútua, responsabilidade, democracia, igualdade, equidade e solidariedade são levados a efeito (RITOSSA, 2008). Com o passar do tempo, foram revistos e atualizados por sucessivos congressos da Aliança Cooperativa Internacional (ACl) e, desde 1995 podem ser assim listados: adesão livre voluntária; gestão democrática pelos membros; participação econômica dos membros; autonomia e independência; educação, formação e informação; cooperação entre cooperativas; e, compromisso com a comunidade.

Por definição, cooperativa é uma associação autônoma de pessoas unidas, voluntariamente, para satisfazer aspirações e necessidades econômicas, sociais e culturais comuns, por meio de uma empresa de propriedade coletiva e democraticamente gerida. O modelo de empresa cooperativa pode ser aplicado a qualquer atividade de negócios, em múltiplos ambientes socioeconômicos. Basicamente, o que a difere da forma organizacional tradicional são a propriedade, o controle e os benefícios estendidos aos seus associados (ACl, 2006).

As sociedades cooperativas podem ser classificadas em graus: primeiro, segundo e terceiro. Uma cooperativa é de primeiro grau ou singular quando é constituída por, no mínimo, 20 pessoas físicas (BRASIL, 1971). A federação ou central de cooperativas representam aquelas de segundo grau e devem ser constituídas por três cooperativas singulares, no mínimo (BRASIL, 1971). Por último, a cooperativa de terceiro grau é aquela cujo quadro social é formado por centrais ou federações de cooperativas (BRASIL, 1971).

As cooperativas atuam num contexto bidimensional: empresarial e social. Assim, além de possibilitarem que indivíduos busquem ferramentas comuns e trabalhem em conjunto na condução de seus negócios, as cooperativas podem ser consideradas como a resposta mais realista para o desenvolvimento e o bem-estar sustentável dos associados e da comunidade. Tais características têm o potencial de amenizar os possíveis efeitos negativos da globalização, como a exclusão social, o desemprego e a depredação ambiental (FREITAS, 2003; PAZ, 2003).

Ao privilegiar pessoas ao invés do capital, as cooperativas, geralmente, não se expandem para além das fronteiras nacionais. Contudo, a intensificação da concorrência nos mercados local e internacional e a oferta de novas oportunidades nas economias dos países em desenvolvimento, impõem às cooperativas a necessidade de formular novas estratégias que, igualmente, protejam mercados tradicionais e permitam a conquista de novos negócios. Seu crescimento futuro, reconhecem as cooperativas, requer reconsiderar suas fronteiras de atuação, sua produção e seus sistemas de mercado tradicionais (USDA, 2002). Para Zylbersztajn (2002) o êxito na área internacional depende da adoção de estratégias antes ignoradas pelas cooperativas, tais como o controle de qualidade e sanidade dos alimentos e a preocupação cm o atendimento das exigências do mercado internacional. 


\subsection{Estratégias de Internacionalização}

A internacionalização pode ser entendida segundo Dal-Soto et al (2007, p. 41) “como um processo crescente e continuado de envolvimento das operações de uma empresa com países fora de sua base de origem".

As estratégias adotadas pelas organizações para alcançar a internacionalização diferem entre si e podem muitas vezes apresentar configurações específicas para alcançar tal objetivo estratégico. As cooperativas, por exemplo, podem perseguir as mesmas estratégias que outras empresas, inclusive as das multinacionais (PETERSEN, 2004). O retorno econômico tem um grande peso na decisão de internacionalizar, mas outros benefícios podem ser citados, entre os quais: o acesso a novas fontes de informação, a canais de distribuição e a competências essenciais para a inovação tecnológica da cooperativa (THEUVSEN; EBNETH, 2005). Mai ainda, a internacionalização pode ser viabilizada por meio da consolidação de associações estratégicas com o objetivo de desenvolver projetos específicos em conjunto ou para garantir a cooperação em um determinado negócio (WRIGHT; KROLL; PARNELL, 2000).

Partindo do pressuposto que a internacionalização requer decisões coerentes de longo prazo e um aporte de capital considerável, a Federação das Cooperativas Dinamarquesas (FCD, 2000) classifica uma cooperativa como internacional quando pelo menos uma de quatro estratégias de internacionalização é adotada: exportação direta ou indireta, alianças, investimentos diretos no exterior e organização de uma cooperativa transnacional, ou seja, uma cooperativa com associados distribuídos em diversos países.

Contudo, os processos de internacionalização têm sido investigados em acordo com três perspectivas básicas: Escola de Uppsala, Planejamento Sistemático e Contingencial. Dentre as três, a perspectiva de estágios seqüenciais de internacionalização da escola de Uppsala, desenvolvida por Johanson e Vahlne (1977, 1990), é uma das principais protagonistas das teorias comportamentais de internacionalização. Essa abordagem propõe que o acúmulo e a integração de conhecimento (empírico) dão suporte às decisões incrementais de comprometimento gradual dos recursos da empresa com o mercado externo.

Paralelamente à aprendizagem adquirida, a teoria de Uppsala indica que novos mercados são selecionados com distância psíquica sucessivamente mais intensa. A distância psíquica é formada por um conjunto de fatores, tais como idioma, cultura, sistemas políticos e práticas de negócios que interferem no fluxo de informação entre a empresa e o mercado. Deste modo, as empresas iniciam seus processos de internacionalização em mercados que podem ser mais facilmente compreendidos, mesmo que geograficamente mais distantes.

De acordo com essa teoria, os modos de entrada em novos mercados seguem estágios sequenciais de internacionalização que se desenvolvem numa cadeia de atividades crescentes de envolvimento com o exterior. Para empresas com menor grau de aprendizagem, os modos de entrada se configuram em exportação indireta e direta, e, para empresas com maior conhecimento acumulado, os modos de entrada incidem na implantação de subsidiárias ou escritórios de vendas, e de unidades de produção no exterior. A seleção do modo de entrada é uma questão crucial para a internacionalização (JOHANSON; VAHLNE, 1977; 1990), pois cada modo determina um grau de comprometimento internacional e de flexibilidade estratégica da empresa.

A percepção de menores riscos e a oferta de maiores oportunidades estabelece o grau de envolvimento e o volume de recursos que a organização investirá no país de destino, sejam eles investimentos estruturais, em marketing, em pessoal, em tecnologia, ou em outras áreas. Nesse modelo, o conhecimento do mercado está diretamente relacionado com o comprometimento estabelecido. Por consequência, quanto maior for a aprendizagem, mais valiosos serão os recursos e maior será a amplitude das operações da empresa com esse mercado.

Assim, a Teoria de Uppsala supera os aspectos puramente econômicos até então priorizados na investigação sobre o tema e passa a contemplar aspectos comportamentais. Nesse sentido os aspectos motivadores e facilitadores podem auxiliar no entendimento do processo de internacionalização.

\subsection{Fatores Motivadores e Facilitadores}

A internacionalização de empresas pode ser incentivada por diversos fatores frequentemente conflitantes que variam de acordo com o momento, os mercados e os modos de entrada. Os principais fatores de motivação internacional elencados por dirigentes de empresas brasileiras, em ordem 
decrescente de frequência, contemplam: oportunidade de lucro, crescimento no mercado internacional, redução da dependência do mercado doméstico, limitação dos riscos em relação ao mercado doméstico, interesse gerencial em relação a atividades internacionais e crenças gerenciais sobre a importância da internacionalização (HONÓRIO; RODRIGUES, 2006).

As razões que incentivam a internacionalização das cooperativas agropecuárias são, em geral, as mesmas daquelas encontradas em qualquer outra forma organizacional (FCD, 2000). Em especial, a internacionalização de atividades do setor cooperativo é considerada uma das maneiras mais promissoras de acesso a novos mercados e de obtenção de sucesso econômico sustentável (THEUVSEN; EBNETH, 2005). Por consequência, alcançar escala de produção figura como uma grande força motivadora do segmento (DONOSO et al, 2003).

Destacam-se ainda fatores motivacionais, não menos importantes, como o crescimento global, o livre comércio internacional, acordos bilaterais, gradual liberalização comercial de produtos agrícolas, e a possibilidade de adaptação a exigências específicas de mercados individuais (PETERSEN, 2004).

O próprio fato de "ser" cooperativa oferece vantagens, inerentes às suas características, que tendem a facilitar a internacionalização. Seipel e Heffernan (1997) identificam quatro vantagens na operação com cooperativas: consumidores finais alinhados com produtores têm assegurado o fornecimento consistente de produtos agrícolas de alta qualidade; cooperativas são consideradas sócias comerciais éticas e confiáveis; cooperativas podem ser exclusivamente qualificadas para atender nichos de mercado locais e regionais; e, ainda, podem minimizar preocupações com segurança e qualidade de produtos alimentícios.

As cooperativas agropecuárias dos Estados Unidos, atentas a esses facilitadores, parecem estar desenvolvendo suas estratégias globais em torno de três forças auto-declaradas: acesso ao fornecedor do produto bruto; reputação de qualidade e fornecimento garantidos; e, inovação permanente diante do conjunto de indústrias altamente competitivas do segmento (COOK, 2000).

\section{Metodologia}

As escolhas metodológicas feitas neste estudo visam possibilitar ao alcance dos objetivos aqui propostos e, para tanto, foram estruturadas como segue:

\subsection{Especificação do Problema}

O problema de pesquisa proposto “Quais as estratégias de internacionalização adotadas pelas organizações sob análise e quais os fatores que motivam e facilitam tal atividade?" exige que se levante dados referentes ao processo de internacionalização e dos fatores motivadores e facilitadores de tal processo junto ao nível estratégico nas organizações investigadas. Também foram obtidos dados relativos a porte, quantidade de cooperados e setor de atuação das organizações sob investigação.

\subsection{Delimitação da Pesquisa}

Nesta parte do estudo apresenta-se o aspecto metodológico referente aos critérios adotados. A seleção dos métodos mais adequados tem estreita relação com os objetivos e o tipo de fenômeno que se pretende desvendar. Para a investigação ora proposta empregou-se a classificação de Cooper e Schindler (2003), compreendendo oito aspectos metodológicos distintos, dos quais sete serão utilizados. Assim, é possível classificar esta pesquisa como exploratória (propósito imediato de exploração e subsidiar a formulação de hipóteses ou questionamentos para pesquisas futuras); seu método de coleta de dados como interrogação/comunicação. Foi utilizado levantamento tipo survey, realizado dentro de um período de sete meses e empregou questionário estruturado, com escalas ordinais e intervalares, de acordo com o tipo de questão formulada. Do total de vinte perguntas, quatro foram elaboradas com escala Likert de cinco pontos, partindo de "concordo totalmente" a "discordo totalmente" e de "muito importante" a "não é importante".

Em relação ao controle de variáveis ela pode ser classificada como ex post facto pela impossibilidade de manipulação destes elementos; quanto ao propósito da pesquisa pode-se enquadrá-la como descritiva tendo-se em vista que o propósito estabelecido foi conhecer o objeto sem buscar relações causais; no quesito dimensão de tempo, o trabalho realizado representa um corte transversal e no item ambiente é uma pesquisa de campo. 


\subsection{População}

Dados os objetivos deste trabalho, a população escolhida foi a de cooperativas agropecuárias do Estado do Paraná envolvidas em atividades internacionais perfazendo um total de vinte e oito organizações. Como a quantidade de organizações permitia a investigação completa, optou-se pelo censo. Ao final, do total de organizações contatadas, vinte e um questionários (75\%) foram recebidos, sendo que dezenove $(67,9 \%)$ foram considerados válidos.

Em virtude do tamanho reduzido da população em estudo, os dados coletados na survey receberam tratamento estatístico não-paramétrico. Além das análises descritivas estatísticas, foram aplicados o teste de Chi-Quadrado, a correlação bivariada de Spearman e o teste estatístico de Kruskal-Wallis considerando para análise o ranking das médias visto que não havia quantidade suficiente de casos para aplicar o teste de Mediana. O nível de significância utilizado em todos os testes foi de 0,05.

\section{Análise E Discussão}

A análise e discussão acerca dos resultados obtidos se iniciam com o delineamento e caracterização das fontes de dados para, posteriormente, considerar as variáveis de análise propostas: estratégias de internacionalização e fatores motivadores e facilitadores das atividades internacionais das cooperativas agropecuárias do Estado do Paraná.

\subsection{Caracterização das organizações investigadas}

Das dezenove organizações investigadas, que representam $67,9 \%$ da população de cooperativas agropecuárias do Estado do Paraná envolvidas em atividades de internacionalização, apenas uma delas é classificada como cooperativa central; as demais são cooperativas singulares.

Os respondentes dos questionários considerados válidos têm o seguinte perfil: cinco são diretores ou superintendentes da cooperativa, oito são gerentes e seis pertencem a níveis intermediários como traders, analistas de mercado ou coordenadores de área. O tempo médio de vínculo empregatício dos informantes é de 16,5 anos, com tempos variando entre 2 e 29 anos de casa e, em média, 8,8 anos de tempo no cargo que ocupam, com variação de 1 a 23 anos na função. Mais da metade dos respondentes $(52,6 \%)$ optou pela não divulgação do nome da cooperativa vinculado aos dados dessa pesquisa.

Nas regiões oeste e noroeste do Estado do Paraná se concentram $68,4 \%$ das empresas pesquisadas ou o equivalente a treze cooperativas. A região com menor representatividade estatística foi a norte que registrou a participação de apenas uma cooperativa e a abstenção de cinco. As duas outras cooperativas que não retornaram os questionários estão localizadas nas regiões centro-sul e oeste, respectivamente. Coincidentemente, os dois questionários inválidos também são dessas mesmas regiões. O porte das cooperativas investigadas foi estabelecido a partir da posição em relação à média do faturamento das organizações investigadas,conforme pode-se observar no gráfico 1

Gráfico 1: Participação da comercialização internacional sobre o faturamento total de 2006

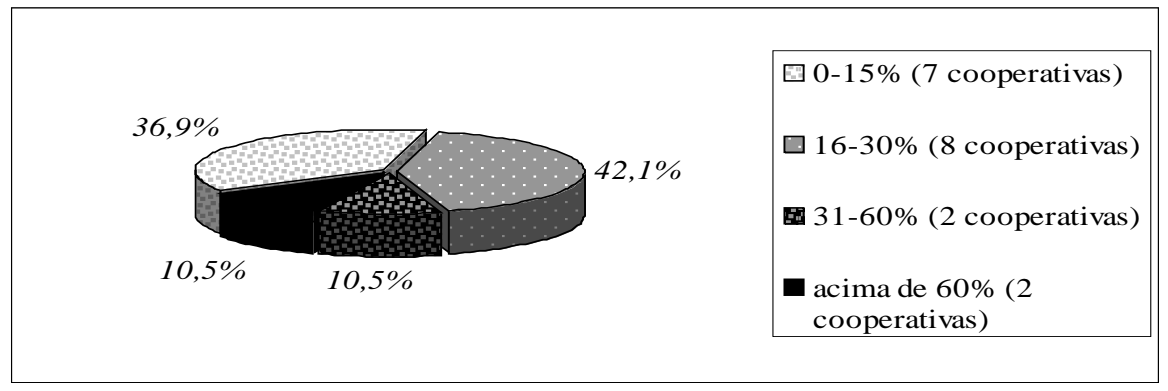

Fonte: Dados da pesquisa

O faturamento total médio de 2006 das cooperativas investigadas foi da ordem de $R \$ 536,6$ milhões, variando de $R \$ 44,5$ milhões a $R \$ 2.662,5$ milhões anuais.

Assim, aquelas com faturamento inferior ao primeiro quartil foram consideradas pequenas; as cooperativas com faturamento superior ao terceiro quartil foram consideradas grandes; as demais foram consideradas de médio porte. 
As atividades das cooperativas sob investigação, classificadas em ordem decrescente de frequência, concentram-se em quatro grandes matrizes de negócios: setor agrícola (94,7\%), comercialização de insumos e mercadorias junto aos cooperados $(84,2 \%)$, setor de carnes $(42,1 \%)$ e setor de laticínios $(10,5 \%)$. Um quinto grupo denominado "outras matrizes de negócios" engloba um conjunto de atividades de menor representatividade percentual individual sobre o faturamento total das cooperativas.

Os produtos comercializados no exterior foram divididos em dois grandes grupos: commodities e produtos semi-industrializados e industrializados, isto é, produtos que sofreram algum tipo de processo industrial de agregação de valor. Em ordem decrescente de frequência, a soja $(63,2 \%)$ e o milho (57,9\%) foram as commodities mais exportadas pelas cooperativas sob investigação, com ampla margem de vantagem sobre o trigo $(10,5 \%)$, o feijão $(10,5 \%)$ e o café $(5,3 \%)$. Da mesma forma, os produtos semiindustrializados e industrializados mais frequentemente exportados são os derivados de carne (31,6\%) e de soja $(21,1 \%)$, seguidos dos derivados de cana-de-açúcar $(15,8 \%)$, lácteos, de milho e de vegetais entalados e congelados (empatados com 5,3\%).

A inserção internacional das cooperativas paranaenses ocorre em maior intensidade nos países da Europa Ocidental, Ásia e Leste Europeu, em ordem decrescente de frequência com 73,7\%, 68,4\% e 42,1\% respectivamente. À exceção do Oriente Médio, esse resultado se encontra bastante próximo às estatísticas nacionais (MDIC, 2006) que registram três países da Europa Ocidental, três países do Oriente Médio, dois países da Ásia, um do Leste Europeu e um da América do Norte nas dez primeiras posições dos destinos atendidos pelas cooperativas brasileiras em 2006. Seguem-se empatados com $21,1 \%$ dos destinos das exportações a América do Norte, América Central e Caribe. Finalmente, a América do Sul, o Oriente Médio e a África se apresentam em posição equivalente com 15,8\% de participação cada.

Em relação ao tipo de produto negociado, 68,4\% das cooperativas negociam, não exclusivamente, produtos semi-industrializados e industrializados com o exterior, comprovando a tendência de redução gradual do setor de concentrar as exportações em commodities tradicionais. O aumento da importância do produto agregado de valor na competitividade internacional do segmento, e a busca por estratégias de maior rentabilidade refletem-se no reduzido número de cooperativas que restringem sua inserção em mercados externos por meio da comercialização exclusiva de commodities: apenas seis.

O teste Kruskal-Wallis aponta para uma diferença no número de cooperados (valor $p=0,023)$ e funcionários (valor $p=0,006$ ) de acordo com o tipo de produto negociado no exterior. As cooperativas com envolvimento em commodities, exclusivamente ou não, apresentam um número maior de cooperados, enquanto que o número de funcionários é maior nas cooperativas que industrializam seus produtos para exportação. A diferença se justifica pela própria natureza das atividades que requer competências distintas para serem executadas. A força de trabalho para fazer frente à produção de commodities tem origem no produtor rural, membro da cooperativa. Por outro lado, o desenvolvimento de produtos agregados de valor demanda um contingente maior de funcionários tendo em vista os processos de industrialização.

\subsection{Estratégias de Internacionalização}

Nenhuma das empresas investigadas ultrapassou os estágios iniciais de envolvimento com o exterior. Ou seja, a totalidade das cooperativas agropecuárias investigadas opera no mercado internacional com um baixo comprometimento de recursos, dando preferência para a exportação via tradings ou agentes comissionados, o que pode ser justificado pela conveniência burocrática e comercial desse modo de entrada. A exportação indireta é a modalidade de internacionalização adotada pela totalidade das organizações investigadas.

Há 11 ocorrências de exportação direta $(57,9 \%)$ para o cliente ou distribuidor no exterior e seis de internacionalização para dentro (inward) $(31,6 \%)$ observada nos casos em que cooperativas importam equipamentos, tecnologia ou matéria-prima. A presença de colaboradores informais no mercado internacional verificada no estudo qualitativo que antecedeu esta pesquisa pode, contudo, ser sinalizador da implantação futura de um escritório de vendas no exterior.

Apesar de a internacionalização poder ser viabilizada através da consolidação de alianças estratégicas com o objetivo de desenvolver projetos específicos em conjunto ou para garantir a cooperação em um determinado negócio, sete cooperativas preferem atuar sem parceiros e quatro encontram dificuldades para encontrar parceiros com os mesmos interesses, o que reforça o argumento de que a empresa 
cooperativa manifesta preocupação em se associar a empresas que não se enquadram nos princípios do cooperativismo e, com isso, ameaçar a estrutura produtiva nas relações com os associados.

Não obstante os modos de entrada indicar um baixo envolvimento das atividades com o exterior, a internacionalização é considerada fundamental para o crescimento das cooperativas agropecuárias pesquisadas. Nesse sentido, $63 \%$ delas classificam o comércio internacional como 'muito importante' e $37 \%$ como 'importante' para que esse objetivo seja alcançado. É possível presumir que em decorrência dessa classificação, a maior parte das cooperativas $(73,7 \%)$ projeta aumentar a participação das vendas internacionais sobre o faturamento total e nenhuma delas tenha manifestado a intenção de reduzir a participação atual. Esses achados corroboram a evidência de que a atuação das cooperativas para além das fronteiras nacionais é necessária para a sua expansão. Além disso, como aponta a teoria de Uppsala, os modos de entrada em novos mercados seguem estágios sequenciais de internacionalização que se desenvolvem numa cadeia de atividades crescentes de envolvimento com o exterior, pode-se especular que a maior participação das organizações investigadas pode crescer à medida que os processos de aprendizado tornam-se mais consolidados nestas organizações.

A frequência das atividades de internacionalização verificada na maior parte das organizações investigadas aponta para a mesma direção. Dez cooperativas (52,6\%) operam em bases constantes no mercado internacional, mesmo nos períodos em que fatores externos, tais como política cambial doméstica e burocracia dos processos de internacionalização, criam barreiras à comercialização, reduzindo provisoriamente sua lucratividade. Três cooperativas (15,8\%), também classificadas nessa categoria de frequência dita constante, optaram por suspender ou reduzir temporariamente as exportações enquanto perdurarem as barreiras. No entanto, seis cooperativas $(31,6 \%)$ declaram que sua atuação no mercado internacional é eventual, dependendo da oferta de condições mais atrativas do que as do mercado interno.

Assim os fatores facilitadores e motivadores desempenham importante papel na intenção de internacionalização das organizações sob investigação.

\subsection{Fatores Motivadores e Facilitadores}

Os fatores que levam as cooperativas a internacionalizar suas atividades foram divididos em dois grupos. O primeiro refere-se a fatores de incentivo e o segundo, a fatores que facilitam a internacionalização de modo geral. Ambos foram classificados a partir de uma escala de 5 pontos. Com a tabulação dos dados foi possível classificar ainda tais fatores conforme a peculiaridade de cada um. Dessa forma cinco tipos de fatores foram encontrados: de ordem financeira, mercadológica, estratégicooperacional, indicadores de inter-relacionamentos e distância psíquica.

Os fatores que incentivam as cooperativas a operar no mercado internacional foram divididos em questões de ordem financeira e de ordem mercadológica (Gráfico 2). Os motivadores são, na verdade, muito similares àqueles encontrados na literatura (FCD, 2000). O aumento da rentabilidade e lucratividade da cooperativa e cooperados, figura como o principal motivo e se mescla com a possibilidade de obter preços mais rentáveis nas negociações internacionais, o segundo item mais apontado.

O conjunto de fatores com os maiores escores indicam que as organizações investigadas consideram a internacionalização como uma alternativa para fazer frente às dificuldades de comercialização no mercado interno, propiciando o escoamento da produção em mercados diversificados que, além de reduzir os riscos de operar em um único mercado, garante a sobrevivência do produtor rural membro, principal agente de fornecimento da empresa cooperativa.

A proximidade entre os resultados dos fatores destaca que o segmento cooperativista vislumbra na internacionalização não só a obtenção de sucesso econômico, mas também dos benefícios que o mercado internacional pode proporcionar entre os quais, o acesso a novas fontes de informação, a canais de distribuição e a competências essenciais para a inovação tecnológica da cooperativa,

Os modos de entrada no mercado internacional com a opção clara por menor envolvimento com o exterior sugerem a falta de interesse em buscar recursos especializados no exterior, tais como capital e mão-de-obra.

O único incentivo que encontra diferença estatisticamente significativa na aplicação do teste de Kruskal-Wallis a partir da frequência de internacionalização da cooperativa, é a busca de alternativas de negociações externas para combater o mercado doméstico estagnado ou saturado (valor $p=0,041$ ), 
identificado entre as organizações que optam pela internacionalização eventual, somente quando encontram condições mais favoráveis de comercialização no exterior, tal como mostrado no gráfico 2

Gráfico 2: Fatores que incentivam as atividades de internacionalização das cooperativas agropecuárias

Aumento de receitas, rentabilidade e lucratividade (cooperativas e cooperado)

Melhores preços de comercialização

Mercado doméstico estagnado ou saturado (excedente de produção)

Garantir a sobrevivência do negócio

Minimizar o risco do negócio

Acesso a novas fontes de informação no exterior

Explorar nichos de mercado

Acesso a canais de distribuição no exterior

Adquirir competências essenciais para inovação e diversificação da produção

Acesso a operações financeiras

Usufruir de incentivos fiscais e tarifários

Existência de parceiros potenciais no país de destino

Alavancagem comercial para reverter capacidade produtiva subaproveitada

Intercooperação (nacional e internacional)

Acesso a recursos especializados no exterior

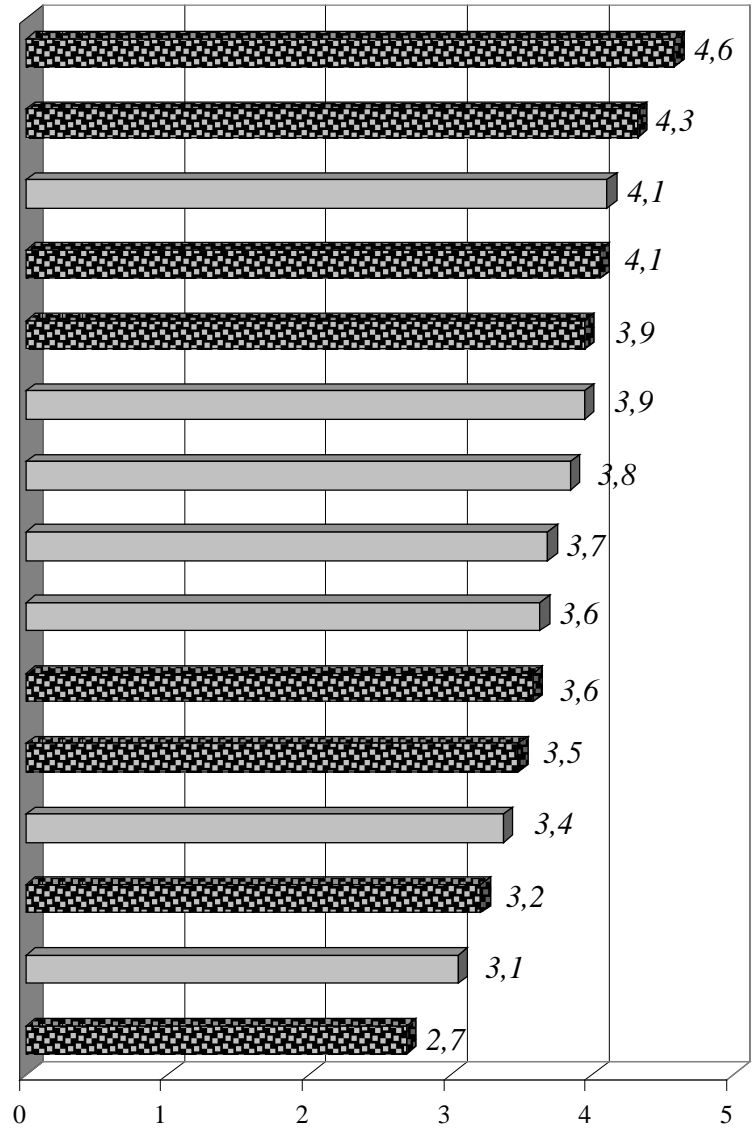

Fatores de ordem financeira

Fatores de ordem mercadológica

Fonte: Dados da pesquisa

Quando considerado o porte das cooperativas, o teste de Kruskal-Wallis aponta diferença estatística significativa apenas para o fator que incentiva a busca da internacionalização para minimizar os riscos do negócio (valor $p=0,028$ ). O grupo que apresenta a menor média é formado pelas cooperativas de grande porte que comercializam commodities e produtos semi-industrializados e industrializados em sua totalidade, sugerindo que a operação internacional a partir de um portfólio diversificado de produtos dilui a exposição ao risco da empresa.

A partir do tipo de produto comercializado internacionalmente, a diferença estatisticamente significativa do teste Kruskal-Wallis (valor $p=0,009$ ) também está na busca da minimização dos riscos do negócio por meio da internacionalização. A menor média verificada está nas cooperativas que comercializam commodities e produtos semi-industrializados e industrializados, confirmando a influência do portfólio diversificado sobre o risco do negócio.

Aspectos operacionais, especialmente aqueles oriundos da competitividade acirrada de mercados globalizados que demandam a satisfação de certas reivindicações, entre as quais o provimento de certificações de qualidade, de gestão ambiental e de rastreabilidade ou, ainda, de paridade tecnológica com a ofertada nos mercados desenvolvidos, figuram entre os principais fatores que facilitam a internacionalização das atividades das cooperativas, conforme demonstrado no gráfico 3. 
Gráfico 3: Fatores que facilitam as atividades de internacionalização das cooperativas agropecuárias

Possuir certificações que atendem exigências relativas à segurança alimentar

Existência de parceiros potenciais no país de destino

Possuir paridade tecnológica de produção com os mercados desenvolvidos

Ter acesso a canais de distribuição no exterior

Existência de acordos comerciais ou participação em blocos econômicos

Ter acesso a novas fontes de informação no exterior

Mix de produtos industrializados da cooperativa

Ser uma cooperativa

Relações com entidades exportadoras no Brasil

Inter-cooperação (nacional e internacional)

Ter acesso a recursos especializados no exterior (capital, mão-de-obra, etc.)

Rede de contatos com instituições públicas e privadas do país de destino

Proximidade geográfica com o país de destino

Proximidade com a cultura e o idioma do país de destino

Fatores de ordem estratégico-operacional

Fatores indicativos de inter-relacionamentos

Fatores indicativos de distância psíquica

Fonte: Dados da pesquisa

Os dados indicam que o êxito na área internacional, em coerência com o que é apontado na literatura, depende da adoção de estratégias, tais como o controle de qualidade e sanidade dos alimentos e a preocupação com o atendimento das exigências do mercado internacional

Diluídos entre os facilitadores, encontram-se um conjunto de fatores que podem estar vinculados ao princípio cooperativista de educação, formação e informação dos cooperados. A construção de interrelacionamentos com agentes diversos faz frente à necessidade das cooperativas responderem às oportunidades e ameaças decorrentes da abertura de mercados. Isso pode acontecer por meio da informação levada aos produtores membros ou pelo investimento na educação e na formação profissionais dos associados, que se traduzem em ações estratégias correspondentes aos sinais do mercado.

A pouca importância que tem sido atribuída pelas cooperativas ao conjunto de fatores que compõem a distância psíquica, como proposto pelos preceitos da escola de Uppsala, e a localização geográfica do país de destino, suscita dois questionamentos iniciais. Em primeiro lugar, sobre a configuração da pauta exportadora das cooperativas e, em segundo lugar, sobre os modos de entrada adotados na internacionalização.

Mais especificamente, a participação das commodities nas exportações das cooperativas investigadas é uma atividade que, a princípio, não sofre particularmente os efeitos oriundos das diferenças de idioma e cultura. Porém, segue-se que, uma vez sendo a exportação indireta a estratégia de internacionalização adotada pela totalidade das organizações sob análise, não cabe à cooperativa, mas sim ao agente ou à trading considerar a proximidade geográfica uma vantagem competitiva que pode inclusive reduzir custos 
de transporte, um fator crucial em operações com pequena margem de manobra, ou, a distância psíquica, como um obstáculo a ser superado como forma de garantir o fluxo de informações entre a empresa e o mercado.

A classificação desfavorável desses fatores no ranking também permite inferir que o volume de produtos exportados diretamente por 11 cooperativas é ainda incipiente vis-à-vis o total exportado ou que o volume de produtos diferenciados, agregados de valor, que dependem não só das certificações de segurança alimentar, mas fundamentalmente do conhecimento da cultura do país importador, correspondem a uma parcela menos representativa das exportações das organizações sob análise

Não há diferença estatisticamente significativa $(p>0,05)$ observada na aplicação do teste Kruskal-Wallis seja na associação dos facilitadores com a frequência exportadora, seja na associação com o porte das cooperativas. Assim pode ser afirmado que as estratégias passíveis de serem adotadas sob essa perspectiva, que facilitariam o ingresso no mercado internacional, são utilizadas de maneira equivalente pelas cooperativas investigadas

No entanto, ao considerar o tipo de produtos comercializados no exterior, o teste Kruskal-Wallis acusa diferença estatisticamente significativa para dois facilitadores: relações com entidades exportadoras no Brasil (valor $p=0,037$ ) e proximidade com a cultura e o idioma do país de destino $($ valor $p=0,016)$. Ambos os fatores apresentam médias superiores para o grupo que comercializa somente commodities no exterior, que é formado em sua maioria por cooperativas de pequeno porte. É factível supor que a falta de contato direto com o mercado externo promovida pelo uso intensivo de agentes e tradings, aliada à necessidade de prospectar novas possibilidades de comercialização, apontem para a busca de mercados que possam ser mais facilmente compreendidos dada a falta de experiência acumulada nessa atividade. Nesse sentido, os relacionamentos com entidades que prestam auxílio às empresas para divulgar e negociar seus produtos no exterior são fundamentais para a superação das dificuldades iniciais da nova modalidade de produtos pretendidos à exportação.

\section{Conclusões e Considerações Finais}

São vários os fatores e indutores que explicam porque as cooperativas agroindustriais internacionalizam-se ou não, os quais têm raízes econômicas, sociais, políticas, ambientais e, até mesmo culturais. Porém, nas organizações investigadas, as estratégias de internacionalização não ultrapassam os estágios iniciais de envolvimento com o exterior. As exportações indiretas e diretas têm sido os modos de entrada adotados pelas cooperativas para atender principalmente os mercados da Europa Ocidental, Ásia e Leste Europeu. A frequência observada nas atividades de internacionalização demonstra a preferência das cooperativas por operações em bases constantes, mesmo nos períodos em que fatores externos reduzem provisoriamente a lucratividade. As demais revelam influência de fatores conjunturais na decisão de internacionalizar suas atividades. Não obstante os modos de entrada indicarem um baixo envolvimento com o exterior, o discurso dominante entre os respondentes é que a internacionalização é fundamental para o crescimento e que as organizações projetam aumentar a participação das vendas internacionais sobre o faturamento total.

A baixa participação do mercado sul-americano na internacionalização das organizações investigadas sugere duas considerações. A primeira diz respeito aos incentivos e facilitadores na comercialização de produtos semi-industrializados e industrializados entre os países membros do Mercosul (Mercado Comum do Sul) que, aparentemente, não vem sendo considerados vantajosos pelas cooperativas do Estado do Paraná. Em segundo lugar, não estão sendo observado o conjunto de fatores que compõem a distância psíquica da teoria de Uppsala (JOHANSON; VAHLNE, 1977, 1990) que, paralelamente ao conhecimento acumulado ao longo dos estágios sequenciais de gradual comprometimento das atividades de internacionalização, dão preferência à inserção em mercados culturalmente mais próximos em seus estágios iniciais. Cabe notar que ambas as considerações podem estar sendo influenciada pela intensa atividade de exportações indiretas observada nas cooperativas analisadas, situação em que as decisões quanto à escolha de mercados é transferida para a empresa trading ou para o agente exportador

No que dizem respeito às organizações investigadas, os dados dessa pesquisa indicam que as cooperativas agropecuárias paranaenses têm ainda uma gama de possibilidades adicionais a considerar quando da busca de parcerias empresariais, pois, além do acesso a mercados, há também alternativas estratégicas para aumentar sua rentabilidade e competitividade internacional. 
Os fatores que incentivam as cooperativas a internacionalizar suas atividades são muito similares àqueles que levam as empresas de capital ao exterior. O aumento de receitas, rentabilidade e lucratividade da cooperativa e do cooperado aliado à obtenção de melhores preços de comercialização, figuram como os principais motivos. Destacam-se também um conjunto de fatores que apontam para a necessidade de escoar a produção em mercados diversificados. Esse fator, além de reduzir os riscos de operar em um único mercado, tem potencial para garantir a sobrevivência do produtor rural membro, principal agente de fornecimento da cooperativa. Em menor grau de importância, o mercado internacional proporciona o acesso a novas fontes de informação e a canais de distribuição, além da aquisição de competências essenciais para inovar tecnologicamente a cooperativa.

No que tange às motivações, nem todas foram consideradas de forma semelhante pelas organizações analisadas. As cooperativas com frequência eventual de internacionalização são essencialmente exportadoras de commodities e atribuem ao mercado doméstico estagnado ou saturado um peso maior na utilização desse incentivo. As cooperativas de maior porte conferem à redução dos riscos do negócio um peso menor, enquanto que as cooperativas que negociam ao mesmo tempo commodities e produtos industrializados no mercado externo atribuem um peso maior a esse mesmo incentivo. A frequência de comercialização e o porte das cooperativas não interferem na utilização dos facilitadores. Contudo, as exportadoras exclusivas de commodities dão mais ênfase que as demais cooperativas às relações com entidades exportadoras no Brasil e à proximidade com a cultura e o idioma do país de destino.

Pode-se ainda afirmar que dois resultados da pesquisa merecem destaque. Em primeiro lugar, a diversificação de produtos voltada para o mercado externo parece ter importância significativa proporção significativa para as organizações analisadas. As evidências convergem para a importância do produto agregado de valor no aumento das sobras das cooperativas; os nove maiores faturamentos e as treze cooperativas classificadas por porte médio e grande têm sua comercialização internacional atrelada a produtos semi-industrializados e industrializados. Além de ser imperativo o rompimento das barreiras protecionistas impostas aos produtos comoditizados, a agro industrialização aumenta a competitividade global das cooperativas e permite a adoção de estratégias diferenciadas com produtos de maior margem. Em segundo lugar, pode ser destacado o baixo envolvimento das cooperativas com o exterior a partir dos modos de entrada selecionados e da tímida participação das vendas externas na base de comercialização das cooperativas, principalmente daquelas de grande porte. Esse tipo de cooperativa registra menos de $25 \%$ de comercialização internacional.

Em conclusão, é necessário melhor compreender o processo de internacionalização e as estratégias de diversificação, redefinindo prioridades dos vários segmentos do agronegócio, particularmente, das cooperativas agropecuárias, envolvidos nesse modelo de expansão comercial. Por outro lado, em um cenário de rápidas mudanças, a pouca inserção das cooperativas agropecuárias no comércio agrícola e pecuário internacional denota, em acordo com o proposto pelo Modelo de Uppsala, a perda de acesso à importantes mercados consumidores, bem como, a redução de fluxo de comércio, ocasionando a redução progressiva da inserção brasileira no cenário agropecuário mundial.

\section{Pesquisas Futuras}

Os estudos das estratégias de internacionalização das cooperativas agropecuárias brasileiras são ainda incipientes e precisam ser aprofundados. Dessa investigação, surgem alguns questionamentos que podem ser considerados em pesquisas futuras.

Primeiramente, um dos princípios do cooperativismo advoga a cooperação entre cooperativas. Nas cooperativas agropecuárias paranaenses, a inter-cooperação tem a preferência das cooperativas de menor porte, exportadoras exclusivas de commodities, em detrimento de possibilidades outras de maior envergadura de cooperação. Assim, a aversão das médias e grandes cooperativas e as alternativas por elas privilegiadas precisa ser mais bem compreendida.

Segundo, a adoção de estratégias de baixo envolvimento com o exterior não encontra respaldo diante do porte, dos tipos de produtos negociados e da estrutura disponível em diversas cooperativas. Ainda que o acesso ao mercado internacional se apresente como um desafio a ser superado, nenhuma cooperativa vai além da exportação direta para entrada nos mercados externos. Interessante verificar por quê desse fenômeno. 
Terceiro, o segmento reclama a inércia do governo federal no que tange a realização de acordos comerciais bilaterais e a participação em blocos econômicos como forma de impulsionar a internacionalização das cooperativas. Contudo, os incentivos e facilitadores na comercialização de produtos semi-industrializados e industrializados entre os países membros do Mercosul não vêm sendo considerados vantajosos pelas cooperativas. Nesse sentido, futuras pesquisas podem identificar os fatores preponderantes que incidem nessa dinâmica, sejam eles relacionados ao tamanho ou ao poder aquisitivo dos mercados pretendidos.

E, finalmente, no Estado do Paraná, apenas pouco mais de um terço das cooperativas agropecuárias internacionalizam suas atividades. A inclusão, em pesquisas futuras, das cooperativas que limitam sua área de atuação exclusivamente ao mercado doméstico, poderia oferecer um panorama mais abrangente acerca das condições que facilitam ou restringem seu acesso aos mercados internacionais.

\section{Referências}

ACI - ALIANÇA COOPERATIVA INTERNACIONAL. What is a co-operative? Disponível em: <http://www.ica.coop/coop/index.html>. Acesso em: 19 dez. 2006.

BRASIL. Lei 5764, de 16 de dezembro de 1971. Define a Política Nacional de Cooperativismo, institui o regime jurídico das sociedades cooperativas, e dá outras providências. Diário Oficial da União, Brasília, 16 dez. 1971.

COOK, M.L. Cooperatives and globalisation. In: Workshop Internacional de Tendências do Cooperativismo: reconversão produtiva, fusões e a internacionalização de negócios, 2, 2000, Ribeirão Preto. Anais... Ribeirão Preto: Fundace, 2000.

COOPER, D. R.; SCHINDLER, P. S. Métodos de pesquisa em administração. Porto Alegre: Bookman. 2003.

DAL-SOTO, F.; PAIVA, E. L.; SPUZA, Y. S. Análise de competências organizacionais na internacionalização de empresas da cadeia coureiro-calçadista. Revista de Administração de Empresas, v. 47, n. 3, p.40-52, 2007.

DONOSO, I.; RUDZKI, R.; SHADBOLT, N.; BAILEY, W. The internationalization of agricultural co-operatives: critical factors in development. Australasian Agribusiness Perspectives Papers, New Zealand, July, 2003.

FAO - Food and Agriculture Organization. Agricultural cooperative development: a manual for trainers, 2001. Disponível em: <http://www.copacgva.org/idc/fao-idc2001.htm>. Acesso em 09 jan. 2006.

FCD - Federação das Cooperativas Dinamarquesas. Transnational co-operatives: perspectives for admission of members abroad and cross-border mergers, 2000. Disponível em:

<http://www.danskeandelsselskaber.dk/view.asp?ID=11940>. Acesso em 08.01.2007.

FREITAS, M. L. Cooperativismo: uma visão estratégica - competição inusitada. Agroanalysis - Revista de Agronegócios da FGV, v. 22, n. 10, p. 14-16, mar., 2003.

HONÓRIO, L.; RODRIGUES, S. B. Aspectos motivacionais e estratégicos na internacionalização de empresas brasileiras. Revista de Administração de Empresas, Ed. Esp., v. 46, p. 86-98, 2006.

JOHANSON, J.; VAHLNE, J-E. The internationalization process of the firm: a model of knowledge development and increasing foreign market commitments. Journal of International Business Studies, v. 8, n. 1, p. 23-32, 1977. doi:10.1057/palgrave.jibs.8490676

JOHANSON, J.; VAHLNE, J-E. The mechanism of internationalization. International Marketing Review, v. 7, n. 4, p. 11-24, 1990. doi:10.1108/02651339010137414

MDIC - Ministério do Desenvolvimento, Indústria e Comércio Exterior. Secretaria de Comércio Exterior. Exportação brasileira de cooperativas por mercado de destino, 2006.

OCEPAR - Organização das Cooperativas do Estado do Paraná. Estudo sobre a evolução das exportações brasileiras, do agronegócio, paranaenses e das cooperativas, 2006.

OCEPAR - Organização das Cooperativas do Estado do Paraná. Exportações do Brasil, do Paraná e das coooperativas no ano de 2006, maio, 2007. 
ORTIZ, M. Profissionalização amplia exportação de cooperativas. Análise Editorial, 2007. Disponível em: <http://www.analisecom.com.br/entrevistas/entrevista_marciolopesdefreitas.php?acao3_cod0 =fb7c8c1e17 132a7165alfd1c9942ef11>. Acesso em: 09 maio 2007.

PAZ, Y. Cooperativismo: uma visão estratégica - um desafio para o novo século. Agroanalysis - Revista de Agronegócios da FGV, v. 22, n. 10, p. 18-22, mar., 2003.

PETERSEN, S. B. Cooperatives and the EU enlargement. Federation of Danish cooperatives. Agriculture Council of Denmark, 2004. Disponível em: <http://www.danskeandelsselskaber.dk/view.asp? ID =11940>. Acesso em: 08.01.2007.

RITOSSA, C. M. A internacionalização de cooperativas agropecuárias: um estudo multi-método das cooperativas agropecuárias do Estado do Paraná. 2008. 157f. Dissertação (Mestrado em Administração) Universidade Federal do Paraná, Programa de Pós-Graduação em Administração.

ROCHA, A.; FREITAS, Y. A. Estabilidade temporal dos obstáculos à exportação: um estudo exploratório. In: Encontro Nacional da Associação Nacional dos Cursos de Pós-Graduação em Administração, 28, 2004, Curitiba. Anais... Rio de Janeiro: ANPAD, 2004

SEIPEL, M.F.; HEFFERNAN, W. D. The transnational challenge: cooperatives and the global food system. Rural Cooperatives, p. 6-10, Sep./Oct., 1997.

THEUVSEN, L.; EBNETH, O. Internationalization of cooperatives in the agribusiness: concepts of measurement and their application. In: THEURL, T.; MEYER, E. C. (Eds.). Strategies for Cooperation. Germany: Shaker Verlag GmbH, 2005. p. 395-419.

USDA - United States Department of Agriculture. Agricultural Cooperatives in the $21^{\text {st }}$ Century, Cooperative Information Report 60, Nov., 2002.

WRIGHT, P.; KROLL, M. J.; PARNELL, J. Administração estratégica: conceitos, 4. ed. São Paulo: Atlas, 2000.

ZYLBERSZTAJN. D. Quatro estratégias fundamentais para cooperativas agrícolas. In: Seminário de Política Econômica: Cooperativismo e Agronegócio, 14, 2002, Viçosa. Anais... Viçosa: Universidade Federal de Viçosa, 2002. 